\title{
Da tolerância festiva às intolerâncias contemporâneas: sagrados desafios do patrimônio religioso no urbano
}

\author{
From tolerance to contemporary intolerances: sacred challenges of \\ religious heritage in urban
}
De la tolerancia festiva a las intolerancias contemporáneas: sagrados desafíos del patrimonio religioso en el urbano

\author{
Rômulo Artur Alves da Silva'; Larisse Freitas Soares'; Christian Dennys Monteiro \\ de Oliveira ${ }^{\text {III }}$
}

\section{RESUMO}

Este trabalho propõe uma discussão sobre as representações da tolerância cultural diante da promoção das festas religiosas como bens patrimoniais nas cidades. Dessa forma o patrimônio, em escala estadual, ganha aparato jurídico das políticas públicas de fortalecimento da cultura de diversidade. Entretanto, essas políticas também sofrem por iniciativas limitadas e posturas de intolerância no uso do espaço público. A pesquisa apresentada desenvolveu-se como estudo qualitativo e documental, complementado por observações de campo, na cidade de Fortaleza (CE) e suas festividades de 15 de agosto. O patrimônio imaterial religioso, objeto central do estudo, foi demarcado pelas representações midiáticas dos grupos direta e indiretamente envolvidos nos festejos de capitais do Norte, Sul e Centro-Oeste do país. O que completou um levantamento já realizado sobre grandes cidades do nordeste e sudeste do Brasil em outra etapa do estudo patrimônio festivo das festas marianas. Como resultado desse percurso, observa-se as fragilidades do reconhecimento da festa religiosas como patrimônio. E confirma-se a percepção de que as estratégias da tolerância religiosa, diante das intolerâncias institucionais e culturais, ampliam-se conforme se efetivam os registros de salvaguarda.

Palavras-chave: Tolerância; Festa; Espaço Público; Patrimônio Intangível; Cidades Capitais

\section{ABSTRACT}

This paper proposes a discussion about the representations of cultural tolerance in the promotion of religious festivals as patrimonial assets in the cities. In this way, the patrimony, at state level, gains legal apparatus of the public policies of strengthening of the culture of diversity. However, these policies also suffer from limited initiatives and attitudes of intolerance in the use of public space. The present research developed as a qualitative and documentary study, complemented by field observations, in the city of Fortaleza (CE) and its festivities of August 15. The immaterial religious heritage (central object of the study) was demarcated by the media representations of the groups directly and indirectly involved in the celebrations of capitals of the North, South and Center-West of the country. This completed a survey already

I Graduado em Geografia pela Universidade Federal do Ceará. E-mail: romuloarturgeo@gmail.com ORCID: https://orcid.org/0000-00032040-0506

II Graduada em Geografia pela Universidade Federal do Ceará. E-mail: larisse freitas@yahoo.com.br

III Professor Associado do Departamento de Geografia na Universidade Federal do Ceará. E-mail: cdennys@gmail.com ORCID: http://orcid.org/0000-0001-8025-2045 
carried out on large cities in the northeast and southeast of Brazil in another stage of the study of the festive patrimony of the Marian feasts. As result of this path, we can observe the weaknesses of the recognition of the religious feast as patrimony; and it is confirmed the perception that the strategies of religious tolerance, faced with institutional and cultural intolerances, are amplified as the safeguard records become effective.

Keywords: Tolerance; Party; Public Space; Intangible Heritage; Capital cities

\section{RESUMEN}

Este trabajo propone una discusión sobre las representaciones de la tolerancia cultural ante la promoción de las fiestas religiosas como bienes patrimoniales en las ciudades. De esta forma el patrimonio, a escala estadual, gana aparato jurídico de las políticas públicas de fortalecimiento de la cultura de diversidad. Sin embargo, esas políticas también sufren por iniciativas limitadas y posturas de intolerancia en el uso del espacio público. La investigación presentada se desarrolló como estudio cualitativo y documental, complementado por observaciones de campo, en la ciudad de Fortaleza (CE) y sus festividades del 15 de agosto. El patrimonio inmaterial religioso, objeto central del estudio, fue demarcado por las representaciones mediáticas de los grupos directa e indirectamente involucrados en los festejos de capitales del Norte, Sur y Centro-Oeste del país. Lo que completó un levantamiento ya realizado sobre grandes ciudades del nordeste y sureste de Brasil en otra etapa del estudio patrimonio festivo de las fiestas marianas. Como resultado de ese recorrido, se observa las fragilidades del reconocimiento de la fiesta religiosa como patrimonio. $Y$ se confirma la percepción de que las estrategias de la tolerancia religiosa, ante las intolerancias institucionales y culturales, se amplían conforme se efectúan los registros de salvaguardia.

Palabras Clave: Tolerancia; Fiesta; Espacio Público; Patrimonio Intangible; Ciudades capitales

\section{INTRODUÇÃO}

No mundo contemporâneo, as relações homem com o espaço religioso, se redesenharam de diferentes maneiras, mas buscaram padrões culturais. Se ontem o crente que tinha seu santuário apenas como objeto de fé e devoção, hoje se vê atraído por um rol de convivência, valores e novas buscas. O que antes se defenia apenas como "espaço sagrado" passa a transformar-se e desdobrar-se em novos conceitos ou ramificações. O espaço simbólico, em seu fazer festivo, tem sido uma desse ramos.

No símbolo reflete-se conflituosamente uma teia de interações culturais, religiosas e econômicas, fortalecida por políticas públicas e privadas. Se antes só a Igreja detinha o monopólio das politicas quanto as festas devocionais, agora o Estado se interpunha nesse contexto, tomando medida que interferem nos meio de devoção; ou no convívio com as devoções alheias. Eis o desafio da "ordem" patrimonial vigente. A pesquisa, que aqui subsidia a reflexão, teve por base análise de três vetores simbólicos (PAVIS 2008; CABRAL, 2011; OLIVEIRA, 2012) que são frequentemente 
ignorados na caracterização geográfica dos municípios e centros regionais: os processos de comunicação midiática, a visitação turística e ritualização carnavalesca das projeções devocionais. Três movimentos condensados pelo peso de representações políticas ao ancorar na cultura patrimonial das tradições cristãs um polo de formação e valoração da cidadania. Buscou-se também fundamentar a pesquisa considerando como parâmetro as tradicionais devoções das festividades marianas, reler a tolerância nas festividades observando tanto as estratégias devocionais de irradiação (comunicação midiática, visitação turística e ritualização carnavalesca) e quanto as intervenções das políticas culturais (meios legislativos, de patrimonialização e jurídicos). Afinal, são estas últimas as responsáveis por manter as Igreja Cristãs na interface de posturas institucionais públicas e privadas; como se fossem (tanto como se sentem) um misto de Mercado e Estado.

Buscou-se cadastrar, por meios de relatos jornalísticos, os discursos da in/tolerância religiosa. Esta se constitui através da apropriação reducionista de "outro" (diferente promovido a rival/opositor); ou seja, na vinculação tensa com as demais formas de religiosidades socialmente edificadas. Nesse contexto, há uma constante reconstrução do sagrado no espaços pré-existentes, remodelada por diferentes agentes e ações de tolerância, almejando um modelo de pluralidade religiosa.

Em continuidade, emergem questionamentos. De que maneira as comunidades (religiosas ou não) toleram o convívio com outras tradições, especialmente no âmbito do exercício festivo? Na construção de políticas culturais, como bens distintos e coincidentes (no espaço e tempo sagrados) poder ser priorizados? As tensões silenciosas que as Festividades católicas (Caminhada com Maria) e umbandistas (Festas de Iemanjá) reeditam, a cada 14/15 de agosto, em Fortaleza, são exemplo dessa questão. Por isso o artigo propõe a discussão sobre a tolerância religiosa, na dinâmica das intolerâncias culturais e políticas. Em tal dinâmica o patrimônio religioso é apartado pelo interesse fragmentário, ao invés de compor uma unidade coerente e plural.

Dessa forma desenvolveu-se um estudo qualitativo e articulado, estruturado a partir de uma atualização bibliográfica sobre patrimônio imaterial religioso, 
demarcando localmente as representações internas e externas aos grupos; de levantamento midiático das festas nas capitais do Norte e do Sul e Centro-Oeste formulando uma tipologia do patrimônio festivo das festas marianas, conforme a leitura de tolerância cultural; por fim, uma coleta de dados - imagens, vídeos e notícias - das festividades religiosas de 11 capitais outras ( 3 do Sul, 3 do Centro Oeste e 5 do Norte brasileiro), observando o diálogo entre o patrimônio imaterial religioso e verificação dos desafios e estratégias da tolerância cultural no âmbito das religiosidades.

\section{A CONSTRUÇÃO DO SAGRADO NO ESPAÇO: FORMAS E RAMIFICAÇÕES SIMBÓLICAS}

Pode-se conceituar espaço sagrado como um lugar de manifestação ou como uma configuração espacial de materialidade seletiva em conformação simbólica extraordinária. Os "espaços sagrados", portanto, formam miniecossistemas de individualidade e conexão; são unidades representativas da dimensão sagrada e, por isso mesmo, testemunhas do intangível. Acumulam diversas interpretações geográficas, teológicas e humanistas; e parte delas embasam aspectos dos contextos colhidos em nossa pesquisa.

Ao partir uma linha teórica baseada em Eliade (1992), deve-se pensar a noção de espaço sagrado como lócus religioso pleno; uma experiência religiosa no qualificada em um lugar especial. Ali se encontra uma dinâmica locacional devocional, onde a leitura dicotômica sagrado/profano dota tal lócus sacralizado de prerrogativas geradas a partir da hierofania. São prerrogativas capazes de reorganizar o seu entorno e, ao mesmo tempo, fornecer ao fiel a mediação entre ele e a(s) divindade(s).

Essa leitura aponta que cada sociedade requer um ponto fixo para orientar e comunicar seus valores no espaço; sendo a heterogenia espacial capaz de demandar e oferecer o "centro". O espaço, então, ganha essa heterogeneidade quando surge algum tipo de manifestação do sagrado, sendo mediada por símbolos que indicam a 
sacralidade de determinado local. É nesse momento que Mircea Eliade (1992) contribui incisivamente:

É preciso dizer, desde já, que a experiência religiosa da não homogeneidade do espaço constitui uma experiência primordial, que corresponde a uma "fundação do mundo" [...] Quando o sagrado se manifesta por uma hierofania qualquer, não só há rotura na homogeneidade do espaço, como também revelação de uma realidade absoluta, que se opõe à não realidade da imensa extensão envolvente. $\mathrm{A}$ manifestação do sagrado funda ontologicamente $\mathrm{O}$ mundo. $\mathrm{Na}$ extensão homogênea e infinita onde não é possível nenhum ponto de referência, e onde, portanto, nenhuma orientação pode efetuar-se, a hierofania revela um "ponto fixo" absoluto, um "Centro". (ELIADE, 1992 p.17)

Podemos reler a contemporaneidade desse princípio em sociedades "dessacralizadas", que não perdem a necessidade referencial de uma cidade espelho da regionalidade maior, ou capital. Assim, tal lócus especial funda-se como lugar no espaço sagrado; e extrapola seus limites por meio de quatro ramificações: o espaço sagrado, espaço profano diretamente vinculado, espaço profano indiretamente vinculado e espaço profano remotamente vinculado. Demarcando uma espécie de hierofania (como utopia da hierarquia devocional), que Rosendhal vai adotar em sua classificação eliadiana dos espaços religiosos.

Para a autora, o espaço sagrado é como "um campo de forças e de valores que eleva o homem religioso acima de si mesmo, que o transporta para um meio distinto daquele no qual transcorre sua existência" (ROSENDHAL, 2007, p.8). A sacralidade é visível/sensível na organização do espaço; não somente pelos impactos desencadeados pela devoção, mas, também, pela forma essencialmente integrada entre religião e tempo. Assim este influencia como um sentimento de vivência na vida do devoto, por meio de simbolismo e práticas, modelando sua fé e ações voltadas para o religioso. Sua importância, segundo Rosendhal (2007) se materializa e irradiase no espaço, deixando "rastros" perceptíveis:

Os fenômenos religiosos se manifestam num momento histórico e não há fato religioso fora do tempo. Em diferentes contextos sócio- espaciais o fato religioso imprime marcas no espaço. São formas simbólicas, imagens, símbolos e outras portadoras de significados religiosos. (Rosendhal, 2007 p.10) 
Redesenhando o lócus central do espaço sagrado, temos Cassirer (1994), que teoriza a relação do ser humano com a construção de sua realidade: significação/sistema simbólica/o. O homem torna-se o protagonista, dando significados as representações e formas simbólicas do sagrado dentro de espacialidades. Assim, o espaço sagrado não se fixa em uma localidade, mas projetase a partir das experiências do indivíduo.

Baseando-se na fenomenologia cassireriana, Gil Filho (2007) contextualiza as espacialidades do "espaço sagrado". Ele articula instituições religiosas, ritos, tradições religiosas, sentimento mítico, lócus religioso e territorialidade do sagrado. Deste modo, realoca a abordagem cassireriana como:

A noção de espaço sagrado, de base cassireriana, que tipifica a outra abordagem das pesquisas do fenômeno religioso no Brasil, a ênfase se dá nas construções epistemológicas dos fiéis/adeptos; que ao conformarem simbolicamente suas diversas experiências religiosas estruturam o seu espaço sagrado. Assim, neste viés, a tendência é conceber o espaço sagrado a partir das articulações de sentido e significados da realidade religiosa dos sujeitos; ratificando o espaço sagrado como conformação simbólica. (GIL FILHO,2012 p.47)

Dentro do próprio espaço sagrado, podemos destacar mudanças e transformações ocorridas no mesmo, estas se dão em função da temporalidade vivida e das ações desenvolvidas pelas lideranças e participantes dos centros devocionais. Cria-se uma nova teia de espacialidades e ritos voltados agora para uma nova demanda organizacional.

Outro ponto a ser destacado consiste nas relações mundanas que passam a se manifestar quando a dimensão sagrada ganha uma espetacularização, envolvendo mais que a religiosidade praticada. Ao mesmo tempo, pontuando novos valores políticos, econômicos, culturais e possivelmente patrimoniais.

O espaço antes tido apenas como sagrado, passa a apresentar novas características, irradiadas por meio de simbolismo, misticismo e aspectos profanos e sacro-profanos. As interações desenvolvidas podem ser observadas no esquema (Fig. 1), onde se visualiza as ramificações do espaço sagrado como encadeamento entre dinâmicas que interligam os polos mundanos e festivos da sacralização. 
Figura 1 - Esquema: Ramificações do Sagrado ao Sacralizado na construção festiva

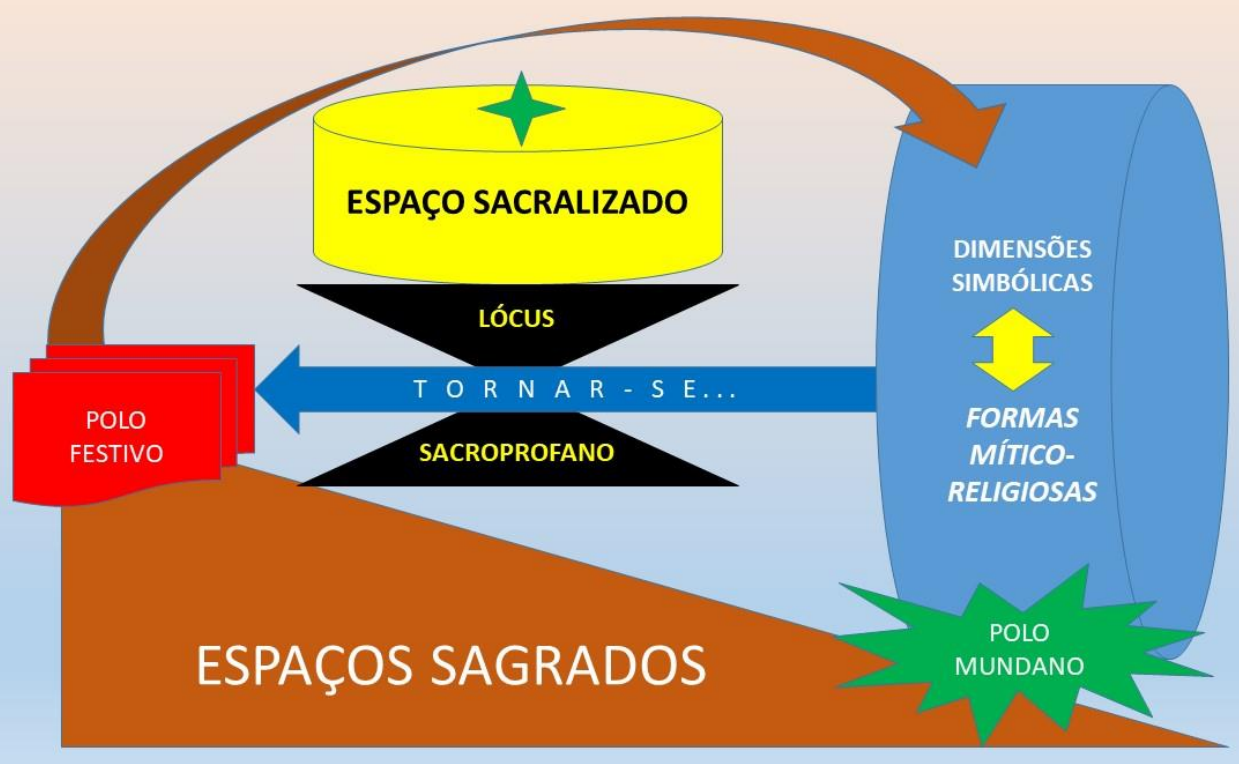

Fonte: Elaboração dos Autores (2017)

Podemos observar as metamorfoses de "fluxo" ou "movimento", que partem das bases do espaço sagrado. Este agora denota de novas características adequandose ao tempo dos desafios mundanos e projetando movimento nas formas simbólicas (mítico e religiosas). Nesta perspectiva, a concepção fundamental para prover o estudo da espacialidade encontra-se na transformação sacro/profana da festa religiosa em "construtora" de um espaço sacralizado. Sua emergência estaria mais próxima dos simbolismos complexos do sagrado em contextos densamente urbanos. O que não anula, mas enriquece, as formulações desenvolvidas por Eliade e Cassirer, tendo em vista as densidades de espaços metropolitanos. Nessa abordagem, a especificação das formas devocionais absorve crenças e práticas religiosas em sintonia com o caótico universo mundano. Embora este se demonstra-se desfavorável ao campo de devoções e dogmas que o sustenta. Por isso a cadeia aparentemente "circular" de acesso à sacralidade emergente aparenta uma realidade tão paradoxal. Pode se ativar pela permanência, pela efemeridade ou simplesmente não se ativar; manter uma latência aparentemente não religiosa. O que torna a abordagem sacro- 
profana do espaço um diálogo multifacetado, com sua expressividade geográfica em uma cultura de metamorfoses.

\section{ESPAÇO DA TRANSFORMAÇÃO SACRO-PROFANA: LENDO O CÍRIO DE NAZARÉ} (PA)

Em que medida o "espaço sagrado" fomenta fluxos e se torna santuário? É possível absorver isso na conjugação de arpectos sacro-profanos, espaço simbólicos e míticos, quando o tempo e reinventa em significativas festividades. Deste modo, as ações desenvolvidas por coletividades e devotos podem redesenhar suas significações, adaptando a festividade ao novo contexto do tempo vivido como sacralidade no espaço. Tais ações, no urbanos das capítais brasileiras, emergem das politicas de incentivo cultural, turístico e midiático. Como exemplo maior tomaremos aqui a projeção patrimonial da devoção mariana do Círio de Nazaré, na Região Norte do país a partir de Belém do Pará (FIGUEIREDO, 2005; SIQUEIRA, 2013.

Uma das festas mais importantes, sobretudo na Amazônia Oriental, é a dedicada a Nossa Senhora de Nazaré, considerada como Rainha da Amazônia e Padroeira dos Paraenses. Esta devoção, que teve origem no interior do Pará, na primeira metade do XVII, numa localidade posteriormente chamada de vila (mais tarde cidade) de Nossa Senhora de Nazaré da Vigia. Já em Belém, capital do GrãoPará, a partir do Sec. XVIII, tornou-se o festival do Círio de Nazaré, tendo em vista o conjunto de eventos que tomam conta das cidades do nordeste paraense ao longo dos meses de setembro e outubro, ininterruptamente todos os anos.

Carregado de simbolismo e ritos, Círio perpassa a espacialidade paraense e irradia-se em dimensão interestadual. Para exemplificarmos os festejos de Nossa Senhora de Nazaré e do Círio acontecem de maneira oficial (feriados estaduais e municipais) nos estados do Pará, Amazonas, Rondônia e Amapá. O ato devocional passa a ser fator de interesse público (PEREIRA, 2003), deste modo diversas políticas culturais passaram a visar o Círio, incorporando a este novos símbolos e espacialidades. 
A exemplo disso temos O Plano Nacional de Cultura (PNC), que foi instituído pela Lei 12.343/2010 e enfatiza o planejamento e implementação de políticas públicas forjadas no tripé de Diversidade/Cultura/Desenvolvimento econômico. É com essa base que os Planos Estaduais de Cultura (PECs) e os Planos Estaduais de Turismo (PETs) são elaborados. Buscando de maneira constante o desenvolvimento econômico e manutenção das tradições pré-estabelecidas. Nota-se aqui como as questões do espaço sagrado, absorvem estruturas públicas e mundanas, para fomentar o espaço festivo em condições de reconhecimento patrimonial. Como se deu com a inclusão do Círio na Lista de do Patrimônio Imaterial da Humanidade, da UNESCO, em 2013 (http://www.unesco.org/new/pt/brasilia/culture/world-heritage/intangible-culturalheritage-list-brazil/cirio-de-nazare/)

Deve-se destacar a presença de vários elementos que combinam, numa mesma festa, a carnavalização, o civismo e a devoção, pois envolvem aspectos essenciais de uma representação simbólica do conjunto da sociedade brasileira, pensada pela ótica do ritual. Com efeito, muitos dos elementos, que compõem o Círio são verdadeiras alegorias, semelhantes aos que desfilam no Carnaval carioca ou no Festival de Parintins (AM).

O dossiê elaborado pelo IPHAN, destaca esses elementos simbólicos históricotradicionais, e novos elementos trazidos para dentro da festividade nas últimas décadas. Observa-se um verdadeiro espetáculo ritual, constituído por objetos e teatralizações de momentos marcantes. No entanto o mesmo enfatiza as políticas culturais adotas, categorizando o Círio como um potencial cultural e socioeconômico:

O Círio atrai turistas, faz lotar hotéis e restaurantes, movimenta a economia da cidade. Não há como negar que isto traz benefícios para o município, mas o importante é estar atento para que os interesses econômicos não venham a desvirtuar o caráter popular e sagrado da manifestação, pois é ele o responsável pela sua longevidade e força vital. Não se pode perder de vista que a força da manifestação está na participação popular. (IPHAN, 2006, 67)

O espaço criado no tempo ritual reordena-se do plano sagrado ao espaço sacro-profano, e exatamente por isso evidencia seu teor simbólico nas dinâmicas que autorizam o reconhecimento dos mitos e das religiosidades como um complexo 
patrimonial. Todo esse movimento criado em torno das espacialidades do Círio de Nazaré, nos proporciona a ideia das transformações vividas nesses espaços míticoreligiosos, considerando a articulação de uma série de representações sócio-culturais e ambientais, baseada na vivência educativa contemporânea. Há portanto uma concialiação do sagrado e o profano através de meios técnicos e politicos.

\section{A TOLERÂNCIA RELIGIOSA NO MEIO FILSÓFICO E JURÍDICO}

A retomada de leituras de Ciências humanas reconstroem a temática da adesão religiosa em um intricada teia de valores mundanos. Formas de fanatismo e tolerância, diante da valorização patrimonial dos bens culturais, transparecem como meios de recomposição dos projetos para uma política cultural pós-moderna, sem arrefecer as dimensões humanistas presente nas manifestões de fé. Daí rever a restruturação do espaço sagrado (teoricamente) e o Círio de Nazaré (empiricamente) como motores de um indispensável debate sobre a importância da pluralidade religiosa no contexto urbano atual.

O debate da tolerância se estende por diversas esferas socias, saindo de classes sociais diferentes, étnicas, raciais e de gênero. Produzindo uma busca constante pelo equilíbrio e pluralismo cultural. De maneira geral, a maior parte das instituições governamentais busca essa convivência harmoniosa, e busca essa por meio de intervenções de uso jurídico e ético-filosófico. Desta forma a tolerância religiosa não se encontra somente na esfera das representações religiosas. Suas ramificações se estendem às instâncias do poder público e seu efeito prospecta precedentes à construção de políticas públicas de resguardo e promoção de bens culturais (materiais e imateriais).

Do religioso ao secular, a polêmica acerca das intolerâncias é antiga. Abordada pelo filósofo inglês John Locke (1632-1704) - que defendia impossibilidade da autoridade política em definir a crença dos indivíduos - o combate à intolerância deve ser feito quando um indivíduo, uma coletividade ou uma religião não possa ser tolerada, ou seja, quando colocam em risco a democracia (LOCKE, 1973, 5;6). Outro 
contemporâneo de Locke, se manifestou a esse respeito foi Thomas Hobbes (1588 1679), afirmando que a intolerância limitava as liberdades dos súditos ao espaço onde o soberano não alcança, incluindo neste o campo das práticas religiosas (SILVA, 2004).

Sob esse aspecto de múltiplas (in) tolerância, a religiosidade brasileira foi constituída socialmente como um fenômeno mútuo de junção e exclusão de dimensões simbólicas religiosas, advindas do tenso contato cultural de povos e grupos distintos, sob a (não) jurisdição de uma devoção hegemônica. Não obstante, o discurso da (in) tolerância religiosa se constitui através da apropriação do outro, ou seja, na vinculação com as demais formas de religiosidades a uma representação fortemente institucionalizada.

\section{O DISCURSO DA TOLERÂNCIA NO CENÁRIO BRASILEIRO}

No Brasil especificamente, a discussão sobre a tolerância religiosa vem configurada por dois fatos marcantes: primeiro, pela tendência ao monopólio da religião católica, que durante séculos predominou, e que nos últimos tempos vem sendo questionada tendo em vista a emergência de um quadro religioso diversifica do que se manifesta no país, sobretudo ao redor da religião protestante que vem apresentando expressiva variação, com destaque para várias correntes, e/ou igualmente, em torno do crescimento do número de adeptos de outras religiões sejam elas de matrizes africanas ou espiritas.

O Catolicismo fundado pela Coroa portuguesa e reforçado pela catequese dos jesuítas, enfrentava a Reforma Protestante, e como "religião universal" atropelava qualquer outro sistema de crenças nativas ou advindas da África negra. Tal hegemonia forjou a base da submissão desses povos, que religiosamente, tiveram de realizar ocultar suas práticas "pagãs" por meio do sincretismo.

Com a formação do estado nacional - e o projeto de manutenção territorial da antiga américa portuguesa como um só país - essa discussão passou apoiar as "vantagens" da identidade brasileira, como uma herança catequética de unidade e controle do Brasil Império. A partir dessa vertente de "intolerância por hegemonia", 
muitos estudiosos da religião defenderam que o sincretismo não só caracterizou o nosso espaço religioso; caracterizou o espaço cultural, influenciando a atualização identitária (ANDRADE, 2002, 17). Tal relação entre sincretismo e pluralismo, coloca de maneira visível o padrão de intolerância que sempre esteve presente no desenvolvimento sócio/histórico. Algo que Burity (1997) enfatizou como:

[...] padrão incide sobre a sua (in) capacidade de interpelar os segmentos subalternos da sociedade, os excluídos de diversos matizes, e tem sua mais perceptível expressão nos conflitos do neopentecostalismo com o catolicismo, as igrejas protestantes históricas e pentecostais clássicos e as religiões afro-brasileiras (BURITY, 1997, p. 109).

As dificuldades de convívio entre os vários sistemas religiosos têm se evidenciando à medida que um "pluralismo" desigual força muito mais a intolerância entre os credos que o respeito mútuo. Ficou claro a necessidade de intervenção do Estado, para uma possível amenização dessa discriminação.

A UNESCO, no ano de 1995, reuniu-se para discutir temas ligados à tolerância, na ocasião foi elaborada a Declaração de Princípios Sobre a Tolerância, tomando para si o exemplo e buscando uma tentativa de adequar-se aos acordos o Brasil alterou alguns pontos de sua legislação. Assim a Lei $\mathrm{n}^{\circ}$ 7.716, de 5 de janeiro de 1989, alterada pela Lei $n^{\circ}$ 9.459, de 15 de maio de 1997, considerando crime a prática de discriminação ou preconceito contra religiões. Essa legislação, no entanto, não retira o direito à crítica que os seguidores de uma denominação religiosa (ou mesmo quem não segue uma) podem fazer aos de outra (ou mesmo a quem não segue uma). Portanto ocorre um processo de mascaração do ato de intolerância, outro contraponto a essa lei é a deficiência de meios executivos para a penalização dos crimes.

Em meio ao início do séc. XXI e as acirradas brigas entre as diversas confissões, - Estado, por meio de um aparato jurídico, reforçou políticas de combate a intolerância religiosa, ganhando a adesão e participação dos segmentos religiosos até então marginalizados socialmente. Nesse cenário que em 2007, foi aprovada a Lei $N^{\circ}$ 11.635, de 27 de Dezembro, na qual se instituiu o Dia Nacional de Combate à 
Intolerância Religiosa, com data fixa a ser comemorada anualmente, em todo o território nacional, no dia 21 de janeiro.

Tal proposta constitui uma ferramenta de apelo às instituições e movimentos, promovendo marchas nas principais cidades do país. Vale lembrar que algumas capitais aderiram a criação de delegacias especializadas em crimes de discriminação e intolerância religiosa. Observa-se uma ressonância das políticas culturais desenvolvidas na dinâmica sociocultural de determinados grupos. No entanto, ainda é cedo para afirmar que tais medidas sejam suficientes na promoção de uma nova ordem religiosa na identidade nacional.

\section{UMA INTOLERÂNCIA RELIGIOSA REFERENCIAL EM FORTALEZA (CE)}

A festa oficializada no calendário local ou regional também abre espaço para demonstrações de insuficiencias na política de tolerância. O feriado municipal do Dia da Padroeira (15 de agosto), em Fortaleza, reflete um de seus momentos ritualisticos mais antigos, em meio a dificuldades e preconceitos, quando uma oportunidade de pluralismo cultural acaba sendo desperdiçada. A data foi originalmente criada pelos Povos de Terreiro para marcar o Dia de Iemanjá. Ocupando espaços litorâneos pela devoção umbandista, a Senhora do Mar se mantem há mais de 50 anos em festejos. Antes corriqueiro apenas nos terreiros de umbanda, a festa de Iemanjá se fez presente ao ambiente citadino, agora busca maior visibilidade e reconhecimento social, pelo registro patrimonial (Decreto $N^{\circ}$ 14.262, de 30 de julho de 2018 da Prefeitura Municipal).

A festa se desenvolve durante entre a noite de 14 e a manhã de 15 de agosto. $E$ neste último, a tarde, a procissão católica Caminhada com Maria, dá-se todo ano a partir de 2001 (SILVA; OLIVEIRA, 2013), justificando a decretação do feriado da padroeira N. S. de Assunção. Para quem busca as duas festas, não é difícil perceber certa rivalidade que passa dos participantes/fiéis para o público em geral.

Com dois pontos conhecidos de concentração de umbandistas, o dia de Iemanjá avança lentamente no reconhecimento do poder público e na sociedade 
fortalezanse. Tais localidades são a Praia do Futuro, bairro da zona leste onde a Prefeitura mantem certos equipamentos e benefícios (palco, barracas, iluminação e som), mas não garante a segurança do entorno; e a Praia de Iracema, com sua localização mais central, facilitando o apoio da secretarias de governo.

Tendo em vista esse suporte da Prefeitura de Fortaleza, o que mantêm o Dia de Iemanjá nas sombras para boa parte da sociedade? Como a população observa a distância as comemorações? E quais sentimentos perpassam o relacionamento com tais ritos no exato Dia da Padroeira?

Segundo Pereira (2016) existe uma relação permanente entre as lutas diárias e a omissão da segurança na Festa de Iemanjá. Tal enfrentamento se arrasta historicamente, marcado por violências (sutis e explícitas) na relação de intolerância contra seus praticantes. A festa na Praia do Futuro é marcada por esse "estigma", sendo vários os fatores que mantêm a festividade como algo incômodo aos olhos do público. Arrastões, furtos, falta de iluminação, disputa de espaço com barraqueiros são apenas a ponta do icerberg das dificuldades vividas pelos umbandistas. Em meio a isso, adotou-se a Praia de Iracema como um local alternativo nas comemorações dos dias 14 e 15 de agosto.

A Praia de Iracema tem se mostrado mais receptiva ao arranjo das comemorações dos terreiros, ajustando-se por sua maior centralidade urbana. Transporte público com mais linhas, melhor iluminação e policiamento são fatores que potencializam a visibilidade da Festa. No entanto, há certo receio por parte da União Umbandistas frente a essa mudança, o que já reflete as tensões frente ao processo de patrimonialização do Dia de Iemanjá, concluído em setembro desse ano (vide https://www.fortaleza.ce.gov.br/noticias/registro-da-festa-de-iemanja-comopatrimonio-imaterial-de-fortaleza-sera-votado-nesta-sexta-feira ). Pai Raimundinho Dente de Ouro, representante do Centro Cultural de Umbanda da Rainha da Justiça Sincera, questiona o posicionamento da União, salientando as melhorias da comemoração no novo local. 
violência até uma delegada esteve lá... Na praia de Iracema temos mais segurança e visibilidade, a Prefeitura está nos apoiando e vamos ficar aqui".

Observa-se certas divergências entre os terreiros, principalmente na questão do local de realização da Festa de Iemanjá. Contudo, a mesma não se resume apenas nesses dois pontos, vários outros locais na orla litorânea metropolitana recebem oferendas a deusa do mar. Em Fortaleza (Mucuripe e Meireles), em Caucaia (Cumbuco e Icaraí) e em São Gonçalo do Amarante (Pecém). Isso sinaliza que o ritual de homenagens é mais interdependente da condição praiana para aproximar-se da divindade do que demandante de uma localidade de origem.

Sendo o Dia de Iemanjá o mesmo da Padroeira, N. S. de Assunção, o contraste dessas tensões mostra-se diametralmente oposto à ostensiva unidade público/privada e organizacional a fim de garantir a realização da Caminhada com Maria. A simultaneidade das festividades ocorre para garantir distinção em todos os sentidos, mesmo perpassando áreas muito próximas.

Realizada desde 2001, a Caminhada com Maria (no formato atual) ocorre como sinal de apropriação definitiva da Arquidiocese de Fortaleza, sobrepondo-se a um evento exclusivamente de bairro (Vila Velha/Barra do Ceará), até a década anterior. Inicialmente organizada pela Paróquia de Nossa Senhora de Assunção, nos últimos anos ganhou várias parcerias para o seu planejamento, destacando o Governo municipal e estadual e a Comunidade Shalom.

O translado da santa, desde 2014 elevado a patrimônio imaterial brasileiro (http://tribunadoceara.uol.com.br/noticias/cotidiano-2/caminhada-com-maria-edeclarada-patrimonio-cultural-imaterial-do-brasil/), reúne em seu cortejo cerca de um milhão de fiéis e espectadores, mudando a paisagem urbana dos bairros do oeste da cidade. De todos os pontos de vista, a mobilização do poder público se faz monumental nessa a Caminhada.

Envolvimento de várias secretarias (saúde, segurança, transito) e autarquias municipais, ruas fechadas e fluxo redirecionados são alguns dos condicionantes que promovem a Caminhada com Maria à condição de festa principal da cidade. Todo esse aparato urbano e governamental permite designar a ação do estado como 
operação laica e católica, em um só tempo. Ali, onde as políticas de apoio a um evento religioso, na confissão hegemônica poderia reunir outras manifestações da cultura popular e religiosa, o Estado apenas reforça a própria hegemonia vigente. É sintomático que então Secretário de Segurança Pública do Ceará, durante a coletiva de imprensa dos organizadores, afirme esse laço sacro-político.

[...] Agradecer primeiramente a Nossa Senhora e ao arcebispo Dom José Antônio e firmar nosso comprometimento... Sobre a segurança durante o dia 15, estarão trabalhando de maneira conjunta a Polícia Civil, Polícia Militar e Guarda municipal, para manutenção da ordem e segurança dos fiéis... teremos o apoio ainda do Corpo de bombeiros e helicóptero do CIOPAER".

Segundo Silva (2012), o contexto da festividade não se resume mais unicamente às motivações religiosas da cidade. Avança valorização dos organismos gestores na escala metropolitana. Demonstrando um modelo religioso contemporâneo em plena sintonia com a metropolização hodierna.

O reflexo de todo esse aparato público, também se consolida na criação do circuito de turismo religioso fortalezense, pois a Caminhada com Maria aparece em destaque no calendário do mês de agosto, em relativo ocultamento de outros, como o próprio Dia de Iemanjá. As duas festividades permeiam limites segregacionistas, anulando ou impedindo o diálogo entre seus participantes e organizadores. Seus espaços comuns, suas reverências ao simbolismo feminino e suas raízes históricas na conformação da cidade são ignoradas. Daí um festeja em dicotomia com o aval do poder público e da sociedade Civil.

Assim sendo, como enfrentar essa fragilidade patrimonial tão enraizada? Existem meios desse pluralismo integrar Iemanjá / Assunção como bens religiosos da cultura Fortalezense? Projetando possíveis equivalências em outras capitais, tais questionamentos reforçam a demanda pela formulação de políticas públicas voltadas à prática da tolerância efetiva; e ao incentivo no respeito com diálogo mútuo entre as diversas crenças religiosas. Vemos ainda em meio a um amplo debate de tolerância religiosa a manutenção de antigos (pré)conceitos e rivalidades no meio sociocultural brasileiro. 


\section{DA PROPOSTA ESTABELECIDA... CONCEPÇÕES INICIAIS}

Parte da investigação proposta do presente artigo tem sua motivação inicial na condução do projeto de pesquisa Estratégias De Irradiação Devocional e Política Pública de Tolerância, no Patrimônio Religioso dos Estados Brasileiros (N/S), desenvolvido no ano de 2016/2017. A proposta do projeto em questão apresenta um desafio de ordem ético-política: Como lidar com as representações da tolerância cultural diante da promoção dos bens (materiais e imateriais) a patrimônio religioso? A pesquisa assume uma escala estadual ganhando aparato jurídico das políticas públicas culturais. O núcleo da pesquisa reside de construção de uma metodologia exploratória, capaz de ampliar as tipologias desse processo de modelagem de um bem religioso. Um bem, conforme lembramos a versão anterior, cada vez mais integrado à dimensão patrimonial da cultura e da espiritualidade, na escala do mundo-lugar (MARANDOLA JR; HOLZER; OLIVEIRA, 2012) e no itinerário devocional que redesenha a fé cristã insígnias pós-modernas (DEBRAY, 2004).

Alvo fundamental na avaliação do quanto se demanda, entre tantas políticas públicas atuais, uma política capaz de enfrentar os desafios culturais de promoção, diversidade, tolerância e gestão do patrimônio religioso. Trata-se da reformulação de um objeto vinculado a capacidade territorial de irradiação: da escala municipal representativa das "redes de lugares" à escala estadual, representativa das "regionalidades federativas".

Dentre a observação do aparato estratégico dos eixos apontados no projeto de pesquisa visualizados em conjunto, ainda que parcialmente, nas festividades marianas analisadas em campo, constata-se: tais eventos registrados como bens culturais imateriais, coexistem com identidades religiosas prejudicadas pela ostensiva presença cristã no domínio do espaço público urbano. Embora essas mesmas confissões sejam referências culturais da formação histórico-social brasileira e apresentem constantes pautas políticas públicas, ação afirmativa de direitos sociais e culturais.

Para além da discussão sobre o entrelaçamento sacro-profano dos eventos católicos e sua inserção da lógica globalizada, observa-se que a Igreja Católica, em 
linhas gerais, representa a condição do "tradicional" sagrado. Forja o lugar comum que detém continuidade histórica, em seu campo imagético, simbólico e institucional, multiplicado em estratégias devocionais adequado ao modus operandi de um cariz (uma fisionomia) sociológica, apontado por Botelho (2001). Seria ingênuo pressupor que as demais manifestações religiosas, não desenvolvessem diante da sociedade atual um "valor utilitário e econômico" (FONSECA, 2005). O caráter simbólico dessas religiosidades de identificação, são apropriados através de um discurso antropológico da cultura; o que lhes confere visibilidade, intermediado e, de certa maneira, produzido pelo Estado para a instrumentalização de políticas culturais. Daí termos tanta abertura para reivindicação dos espaços culturais de outros credos e matizes na cidade; mas apenas exercermos a reprodutibilidade das mesmas hierarquias intolerantes.

Fonseca (2005, p. 42) explicita essa característica, separando as esferas dos bens culturais e patrimoniais que "a intermediação do Estado no segundo caso, através de agentes autorizados e de práticas socialmente definidas e juridicamente regulamentadas, contribui para fixar sentidos e valores, priorizando uma determinada leitura". No entanto, supor que a reprodução desta leitura seja totalmente incorporada socialmente, ao ponto de suplantar as visões de mundo também culturais e dominantes, no caso é simplista. Sob essa contextura podemos enfocar a vinculação sincrética religiosa brasileira, o discurso do Estado de preservação de identidade e continuidade da religiosidade afrodescendente como patrimônio cultural e a histórica intolerância religiosa a essas designações de fé. Logo, outra forma de leitura se constrói na esfera da (in)tolerância religiosa.

A necessidade de se apontar a derivação do termo se encontra na própria caracterização do discurso, uma série de problemáticas nem sempre claramente diferenciadas e/ou definidas e seus desmembramentos nas políticas públicas. O discurso da tolerância religiosa, nesse contexto, se avoluma em torno de uma metodologia de apoio a pluralidade; e tal pluralidade se institucionaliza num espaço social permitido no discurso do Estado. Sobre essas preocupações, a partir da observação do espaço simbólico católico nas estratégias devocionais das festividades 
marianas, a vinculação ao aparato jurídico-institucional intrínseco desemboca na aplicação das políticas públicas parciais. Tal parcialidade, em relação as demais formas de religiosidade brasileira, se constrói na ideia de uma aceitação da intolerância, elaborada através dos relatos de violência veiculadas em mídia digital oriundas regiões Centro-Oeste, Norte e Sul entre os anos 2016-17, completando sem maiores modificações o que no ano anterior contatamos nas regiões NE e SE.

Os apontamentos a seguir se referem as reflexões iniciais sobre a convergência na tipificação da intolerância religiosa considerando como parâmetro os espaços sagrados, símbolos e ritos institucionalizados, no caso, as festividades marianas, em paralelo a apropriação e desdobramento das demais religiosidades e a inserção destes na dinâmica das relações sociais.

\section{RESULTADOS OBTIDOS... UMA REALIDADE MUITO INTOLERANTE}

O mapeamento esquemático para a construção de um panorama da intolerância religiosa se realiza considerando, principalmente, os relatos de violência com motivações religiosas, menções ao uso do aparato jurídico para romper com o círculo de intolerância e organização das instituições civis veiculados em mídia digital entre os anos 2016/17 ( $1^{\circ}$ semestre). A averiguação envolveu as religiões representadas pelos dados estatísticos no CENSO 2010 - catolicismo, protestantismo, espiritismo - ainda que, na construção da pesquisa, concentre-se na representatividade das religiões de matrizes africanas na quantificação de relatos de Intolerância e Violência religiosa. Ressalta-se que identificamos casos de intolerância num espectro maior de religiosidades (regionalidades) e estas foram contempladas no escopo do trabalho.

As palavras-chaves utilizadas para a pesquisa na ferramenta de buscas nos dá um aspecto inicial da representatividade do fenômeno: Intolerância religiosa; Ataque a Igrejas Católicas; Perseguição religiosa; Violência por motivação religiosa; Ataques a religiões afrodescendentes; Ataques a Centro Espíritas; Ataque a religiões pentecostais; Intolerância religiosa no Exame Nacional do Ensino Médio - ENEM. Através da 
metodologia exploratória utilizada se desenhou uma primeira visualização da problemática.

A caracterização dessa imagem superficial aponta aspectos relevantes. Por exemplo, divididas em três blocos regionais, as referências a intolerância religiosa, veiculadas por capital, indica uma escala primária, em números absolutos - sem considerar o montante populacional obtidos através do Censo 2010 e dimensão territorial - das capitais da região Centro-Oeste, a que apresenta maior quantidade de menções é a cidade de Cuiabá (cerca de 70\%). Das capitais da região Norte, Palmas reúne $66,6 \%$ das menções nos sites de busca seguida pela cidade de Rio Branco, com 55,5\%. Na região Sul, a cidade de Porto Alegre reúne 38,4\% dos relatos jornalísticos sobre intolerância religiosa. Dada à desproporção da quantidade de estados que compõem os blocos regionais da pesquisa (Centro-Oeste, Norte e Sul), respectivamente, 4, 3 e 7 unidades federativas, outro aspecto relevante é a equivalência de menções a intolerância religiosa em mídia digital, totalizando 33\% (CO), 45\% (N) e $22 \%(\mathrm{~S})$.

A análise desse bloco de gráficos sugere uma distribuição homogênea de incidência de relatos de Intolerância religiosa nos estados da região norte em contraposição aos relatos da região Centro-Oeste. Como citado anteriormente, o Distrito Federal concentra $42 \%$ das matérias jornalísticas de sua região o que corrobora com dados do Relatório sobre Intolerância e Violência Religiosa no Brasil RIVIR (SDH, 2016) que aponta os dez estados com maior número de denúncias recebidas pela Ouvidoria de Direitos Humanos. O recorte organizado para o mapeamento da Intolerância Religiosa sistematiza a pesquisa segundo alguns parâmetros - Relatos de violência; recorte temporal (2016-17); vertentes religiosas específicas. Logo, num segundo momento, as menções a intolerância nas mídias digitais são afuniladas seguindo os parâmetros definidos.

$\mathrm{Na}$ estruturação dos relatos de violência, distinguiu-se maior incidência dos eventos elencados - impedimentos, perturbação e invasão dos espaços de rito; vandalismo, depredação da estrutura física e danificação dos elementos simbólicos das formas religiosas - símbolos, imagens, ídolos, vestimentas; ameaças, agressão 
física e verbal, assassinatos, menções jurídicas e organizações civis para o combate da intolerância.

Das matrizes religiosas selecionadas para o estudo, o maior número de menção a violências cometidas é direcionado as religiões de matrizes africanas, em segundo, a religião católica, seguida pelo protestantismo. Segundo o balanço de atendimento as vítimas de intolerância religiosa representadas no Relatório de Intolerância e Violência Religiosa no Brasil - RIVIR $($ SDH, 2016) das denúncias que chegaram à ouvidoria e instâncias públicas entre 2012-15, 27\% das 394 denúncias referiam-se as religiões de matrizes africanas.

Não obstante, a mensuração dos dados disponibilize parâmetros sobre a reflexão da problemática, a discussão da pesquisa busca contribuir na elaboração de caminhos plausíveis ao tratamento das representações da (in)tolerância religiosa. Na análise das reportagens veiculadas, depara-se com a relação do poder público como gestor indireto dos espaços sacralizados, em relativa sintonia com seus discursos eclesiais. A priori, além a disputa simbólica e nos desdobramentos dos campos da cultura religiosa, observa-se a cisão com a diversidade de grupos interessados; o que amplifica os problemas intolerância. Nas falas de entrevistados pelas diversas reportagens colhidas, é possível constatar, não só a reivindicação das espacialidades de direito ao culto - por confissões e setores relativamente marginalizados, dentro e fora do cristianismo - como a aclamação de posicionamentos em prol de políticas públicas culturais mais de maior laicidade.

O que significa dizer que não se trata de uma mera disputa pela mudança da hegemonia cristã católica, frente ao crescimento evangélico, espiritualista ou afrodescendente. Trata-se de firmar/fixar novas bases do convívio social na complexidade do espaço público urbano, em duas frentes: ampliando a visibilidade dos cultos específicos da identidade religiosa que reivindica seu espaço e demarcando a cooperação com outros direitos fundamentais da sociedade tão ameaçados quanto o direito a toda e qualquer forma de religiosidade contemporânea. Por isso a festa de santos e de irmandades aproximam-se cada vez mais das manifestações político-culturais, como por exemplo aquela que no dia 21 de 
janeiro, que demarca o Combate a intolerância religiosa; tanto em Fortaleza, quanto em outras importantes cidades brasileiras.

\section{CONSIDERAÇÕES FINAIS}

As festas religiosas ainda demonstram a força identitária de uma cultura e a vitalidade de um arranjo social de resistência e inovação, diante de todo tecnicismo que a urbanização tem, sedutoramente, fomentado para fazê-las desaparecer. Contudo, são poucas aquelas que compreendem o papel da cooperação entre visões de mundo distintas, mas que necessitam dialogar efetivamente e especialmente nos momentos de celebração. Daí a constituição de uma fragilidade ostensiva por parte das instituições públicas, ao contrário do exemplo (nunca sem conflitos) do Círio de Nazaré, fomentam o patrimônio imaterial da festa adicionando diferentes atores e espaço em sua paisagem patrimonial, agora registrada em várias escalas.

$\mathrm{Na}$ análise dos relatos de intolerância, obtidas pela expansão do projeto Estratégias de Irradiação Devocional às regiões Centro-Oeste, Norte e Sul, observamos maior incidência de casos com essas características: reforço as festividades de um santo ou entidade, em detrimentos a todas as demais expressões de fé que naquele lugar existe. Nota-se, assim um "rompimento" frente às possibilidades e potencialidades de intercâmbios. As confissões religiosas protagonizam novos espaços simbólicos, mas refutam se submeterem à hierarquização dos espaços públicos, como se estes fossem naturalmente préestabelecido para cada uma delas. Além da confluência que parece pressupor uma correlação: alto números de denúncias $\mathrm{X}$ alcance midiático dos relatos de Intolerância. Alguns setores sociais e religiosos conservadores ganham espaço midiático, enquanto a sociedade em geral e as comunidades religiosas em partículas, perdem irreparavelmente muito com essa trama. Para além do discurso valorativo da pluralidade cultural, do resguardo e da promoção dos bens religiosos, a questão patrimonial dos espaços sacralizados não reduz mas amplia os problemas urbanos hodiernos 
Desse modo, o discurso da (in) tolerância religiosa se entrecruza na construção das políticas culturais apresentando medidas paliativas que se associem também a lógica da identidade em função do desenvolvimento econômico. O mapeamento dos estados do Centro-Oeste, Norte, Nordeste, Sudeste e Sul, na tentativa de se construir um panorama da tolerância assinalada pelas especificidades regionais, aponta a heterogeneidade dos discursos que se manifestam no espacialmente através das políticas culturais.

A perspectiva analisada para a construção de políticas culturais de tolerância, resguardo e promoção de bens culturais (materiais e imateriais) aponta que o confronto das identidades sociais construídas nas esferas devocionais abrange uma perspectiva complexa que negam a condição de sujeitos de direito a determinados grupos (minorias) sociais (MIRANDA, 2009), no entanto, os conflitos não se constroem somente na esfera simbólica, o papel jurídico-social do estado vem a negociar o lugar das representações religiosas no espaço público.

Entende-se através da visualização da incidência e conteúdo desses relatos jornalísticos - especialmente em eventos de porte nas grandes capitais brasileiras não desenha uma situação isolada. Sua interpretação no movimento das festividades anualmente realizadas encaminha uma conduta colaborativa da maior urgência, considerando o amplo debate do patrimônio religioso como bem cultural: a recriação de políticas de apoio governamental que efetivamente fomente o encontro das manifestações de fé; não apenas o seu livre e irresponsável direito a manifestar-se com todos os recursos públicos, mas sem a participação de nenhum outro seguimento religioso.

\section{REFERÊNCIAS}

ANDRADE, M. O. de. A Religiosidade Brasileira: o pluralismo religioso, a diversidade de crenças e o processo sincrético. Revista Eletrônica de Ciências Sociais. Número 14 - Set. 2009. http://www.cchla.ufpb.br/caos/n14/6A\%20religiosidade\%20brasileira.pdf. Acesso em: 10 abr. 2017. 
BOTELHO, ISAURA. Dimensões da cultura e políticas públicas. São Paulo em perspectiva, 15(2) 2001. Disponível em: http://www.guiacultural.unicamp.br/sites/default/files/botelho_i_dimensoes_da_cultura_e_p oliticas_publicas.pdf. Acesso em: 18 abr. 2017.

BURITY, J. A. Cultura Política Democrática e Atores Religiosos. Recife: Fundaj, 1997.

CABRAL, Clara Bertrand. Património Cultural Imaterial: Convenção da Unesco e seus Contextos. Lisboa: Edições 70, 2011.

CASSIRER, Ernst. Ensaio Sobre o Homem. São Paulo: Martins Fontes, 1994.

DEBRAY, R. Deus, um itinerário. São Paulo: Companhia das Letras, 2004.

ELIADE, Mircea. O sagrado e o profano. São Paulo: Martins Fontes, 1992. 191p.

FIGUEIREDO, Silvio Lima (org). Círio de Nazaré, festa e paixão. Belém: EDUFPA, 2005.

FONSECA, M. C. L. O patrimônio em processo: trajetória da política federal da preservação no Brasil. 2. ed. Rio de Janeiro: Editora UFRJ; MinC - Iphan, 2005.

GIL FILHO, Sylvio Fausto. Geografia da Religião e Espaço Sagrado:diferenças entre as noções de lócus material econformação simbólica. Curitiba, Revistas UFG, 2012. Disponível em: https://www.revistas.ufg.br/atelie/article/view/18760. Acesso em: 18 abr. 2017.

IPHAN. Instituto do Patrimônio Histórico e Artístico Nacional. Círio de Nazaré. Rio de Janeiro: IPHAN, 2006.

LOCKE, J. Carta acerca da Tolerância. Os Pensadores. São Paulo, Abril Cultural, 1973.

MARANDOLA, E.; HOLZER, W; OLIVEIRA, L.de. (org). Qual o Espaço do Lugar? São Paulo: Ed. Perspectiva, 2012.

MIRANDA, A. P. M. Entre o privado e o público: considerações sobre a (in)criminação da intolerância religiosa no Rio de Janeiro. Anuário Antropológico/2009 - 2, 2010: 125152. Disponível em: http://www.ineac.uff.br/sites/default/files/library/files/06anuarioantropologico-anapaulamiranda1.pdf. Acesso: 21 de mai. 2016.

OLIVEIRA, C. D. M. de. Turismo Religioso: uma Breve Apresentação. Revista turismo e Hospitalidade, São Paulo, p. 1 - 3, 01 set. 2003.

OLIVEIRA, C. D. M. de. Carnavalização e complexidade turística: Formação de paisagens rituais em Eventos no Estado do Ceará. RA'EGA (UFPR), v. 16, p. 1-17, 2008.

PAVIS, Patrice. Análise dos Espetáculos: Teatro, Mímica, Dança, Dança-Teatro, Cinema. S. Paulo: Perspectiva, 2008.

PEREIRA, J. C. A. "Linguagem do Corpo na Devoção Popular do Catolicismo". In: REVER. Revista de Estudos da Religião. No 3 / 2003 / pp. 67-98. ISSN 1677-1222. Disponível em: http://www.pucsp.br/rever/rv3_2003/p_pereira.pdf Acesso em: 7 maio 2017.

PEREIRA, Ilaina Damasceno . Performance e visibilidade da Umbanda em Fortaleza-CE: por uma utopia do direito à cidade. In: Colóquio Internacional de Georítica, 14., 2016, Barcelona. Actas del XIV Colóquio Internacional de Georítica, 2016. v. 1. p. 1-23. 
ROSENDAHL, Z. ESPAÇO, SIMBOLISMO E RELIGIÃO: RESENHA DO SIMPÓSIO TEMÁTICO. Revista Brasileira de História das Religiões - ANPUH. Maringá (PR) v. 1, n. 3, 2009. ISSN 1983-2859. Disponível em http://www.dhi.uem.br/gtreligiao/pub.html. Acesso em: 07 de julh. 2017.

$S D H, 2016$. Relatório sobre intolerância e violência religiosa no Brasil (2011- 2015): resultados preliminares / Ministério das Mulheres, da Igualdade Racial, da Juventude e dos Direitos Humanos; organização, Alexandre Brasil Fonseca, Clara Jane Adad. - Brasília: Secretaria Especial de Direitos Humanos, SDH/PR, 2016. Disponível em: http://www.sdh.gov.br/sobre/participacao-social/cnrdr/pdfs/relatorio-de-intolerancia-eviolencia-religiosa-rivir-2015. Acesso em: 15 mar 2017.

SILVA, A. O Reflexões sobre Intolerância. Disponível em: http:www.espacoacademico.com.br/2004.

SILVA, L. R. T. da; OLIVEIRA, C. D. M. de. A conquista da metrópole profana: uma análise da territorialidade religiosa como instrumento da patrimonialização imaterial em Fortaleza (CE). Revista Brasileira de Ecoturismo, v. 6, p. 65-80, 2013.

SIQUEIRA, J.P.S. A Gestão do Espaço Turístico do Círio de Nazaré de Vigia- (PA). Dissertação de Mestrado. UFPA. 2013. Disponível em http://repositorio.ufpa.br/jspui/bitstream/2011/8215/1/Dissertacao GestaoTuristicoCirio.pd f Acesso em out 2017. 